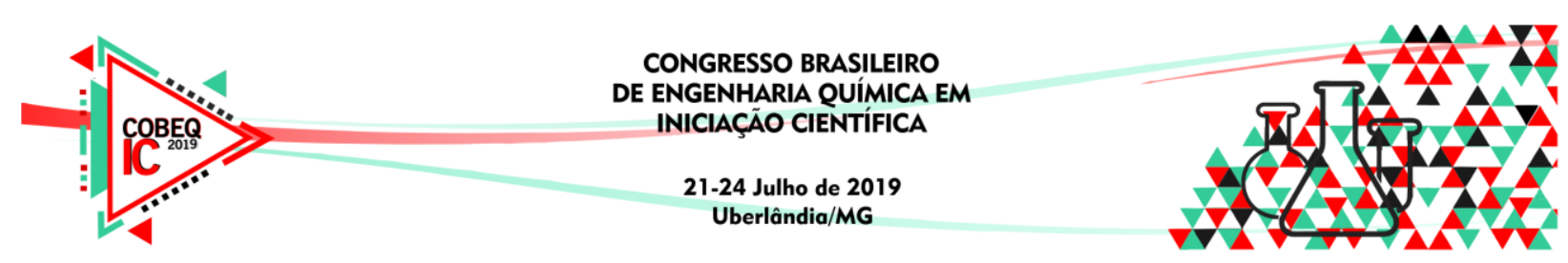

\title{
ULTRAFILTRAÇÃo DA ÁGUA DA CHUVA PARA PRODUÇÃo DE ÁGUA POTÁVEL
}

\author{
FRACARO, G. ${ }^{1}$, BRIÃO, V. B. ${ }^{1}$, BAÚ, S. R. C. ${ }^{2}$, GIUBEL, G. O. M. ${ }^{1}$, PORTELLA, J. R. C. ${ }^{1}$ \\ ${ }^{1}$ Universidade de Passo Fundo, Faculdade de Engenharia e Arquitetura \\ ${ }^{2}$ Universidade de Passo Fundo, Programa de Pós-Graduação em Engenharia \\ E-mail para contato: $150801 @$ upf.br
}

\begin{abstract}
RESUMO - Há uma grande importância em termos de potabilidade de águas, tanto com águas subterrâneas, superficiais e ainda com a captada da chuva. Esta última é geralmente utilizada para limpezas externas ou simplesmente descartada. Este projeto teve como objetivo tratar a água captada da chuva em água potável, pronta para consumo humano através da ultrafiltração. A água tratada com a membrana de fibra oca com $50 \mathrm{kDa}$ atendeu a qualidade de água potável constante no anexo da Portaria de Consolidação ${ }^{\circ} 5$ de 28 de setembro de 2017, destacando uma redução de $100 \%$ de E. coli, $96,7 \%$ na turbidez, $93,12 \%$ de coliformes totais e $50 \%$ de DBO. Após um período de análises diárias, semanais, mensais, o processo se mostra eficiente e capaz de tornar a água da chuva em água potável, para possível abastecimento. A água da chuva nos proporciona fácil acesso comparado a outros métodos, como perfuração para acesso a águas subterrâneas, ou grandes instalações de purificação de águas superficiais.
\end{abstract}

\section{INTRODUÇÃO}

O abastecimento com águas superficiais e subterrâneas são os métodos preferencialmente utilizados, porém a preocupação com a escassez e contaminação da água potável é cada vez maior, principalmente em lugares onde ocorre secas periodicamente e próximos de grandes lavouras, em conta do uso de agrotóxicos. Diante disto, métodos alternativos de captação de água estão sendo estudados, sendo um deles a utilização da água da chuva para fins potáveis, pois no Brasil a água da chuva ainda é utilizada somente para fins não potáveis (BAÚ, 2018).

Segundo a Portaria de Consolidação n ${ }^{\circ} 5$ de 28 de setembro de 2017 que controla e vigia os padrões de qualidade da água para consumo humano, é considerado válido sistemas de captação alternativos de água e estipula padrões de qualidade para esta água (BRASIL, 2017).

Nos processos por separação por membranas, existem as membranas de microfiltração (MF), ultrafiltração (UF), nanofiltração (NF) e osmose reversa (OR). A grande diferença entre essas membranas, é o tamanho de seus poros, quanto menor o poro maior a pressão que deverá ser aplicada e quanto maior a pressão aplicada, maior será o consumo energético (BAÚ, 2018).

A UF trabalha com pressões abaixo de 10 bar, a nanofiltração com pressões entre 5 e 35 bar e a osmose reversa com pressões de 15 a 150 bar. Entre as vantagens da UF estão seu baixo 


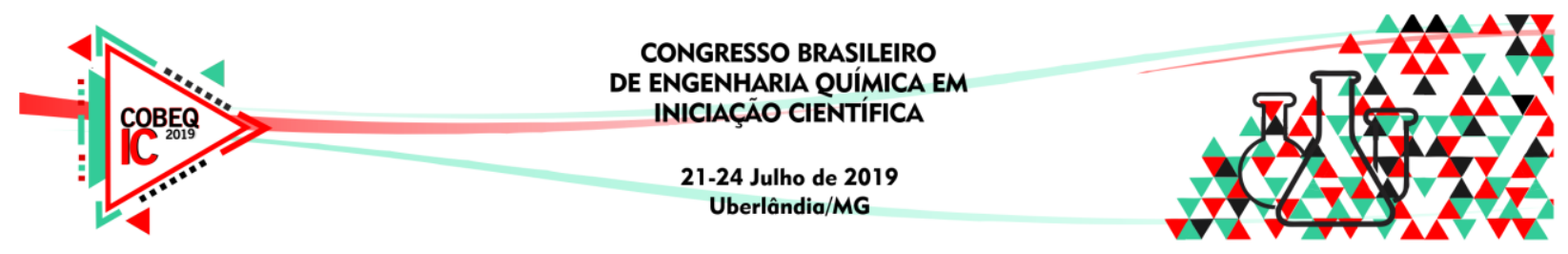

consumo energético, baixo custo de operação, pequena área de instalação e possuem uma vida útil entre 3 a 5 anos, que é a mesma quando comparados as membranas de osmose (BAÚ, 2018).

A ultrafiltração é o processo pelo qual a água é forçada contra a membrana que permite a passagem do solvente (permeado) e retém solutos de alto peso molecular (retido), sendo uma de suas aplicações a produção de água potável (BRIÃO, 2012). As membranas de UF são recomendadas para a produção de água potável pois elas tem grande capacidade de remoção de contaminantes como bactérias, protozoários, vírus, colóides e macromoléculas responsáveis pela cor e turbidez presentes na água, assim reduzindo a demanda de cloro necessária para a desinfecção e consequente formação de subprodutos de desinfecção causadores de gosto e odor (OLIVEIRA, 2010).

Desse modo, o objetivo do trabalho foi produzir água potável a partir da água da chuva, utilizando a ultrafiltração como método de tratamento.

\section{METODOLOGIA}

A captação da água da chuva foi realizada a partir de um telhado, localizado no prédio L1 - Engenharia de Alimentos $\left(28^{\circ} 13^{\prime} 53.5^{\prime \prime S} 52^{\circ} 23^{\prime} 04.6^{\prime \prime W}\right)$ na Universidade de Passo Fundo (BRA-RS), com área aproximada de $90 \mathrm{~m}^{2}$ e conduzida para um reservatório de armazenamento com capacidade de $300 \mathrm{~L}$.

A membrana utilizada para realizar a UF da água da chuva foi uma membrana de fibra oca, fabricada pela Pam Membranas Seletivas e suas características estão descritas abaixo:

a) Material das fibras ocas: poli (éter sulfona);

b) Diâmetro externo da fibras: entre 0,8 e $0,9 \mathrm{~mm}$;

c) Fibras com camada seletiva externa;

d) As fibras de UF apresentam 95,0\% de retenção efetiva para compostos com massa molar superior a $50 \mathrm{kDa}$;

e) A filtração ocorre de fora para dentro das fibras;

f) O extrato ultrafiltrado escoa pelo interior das fibras;

g) Material de construção dos módulos: PVC soldável;

h) Pressão máxima de operação: 5 bar;

i) Temperatura máxima de operação: até $55,0{ }^{\circ} \mathrm{C}$;

j) $\mathrm{pH} 2,0$ a 13,0 .

Para a realização da UF, foi utilizado um equipamento automatizado (Figura 1) e também um software, fornecidos pelo mesmo fabricante da membrana. 


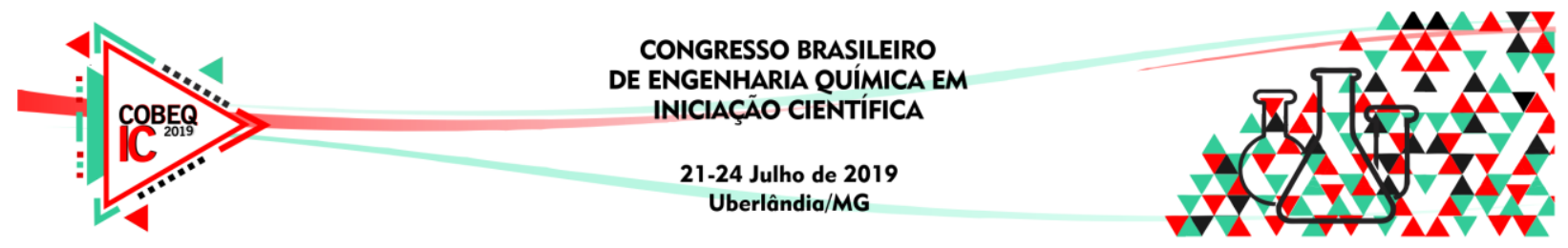

Figura 1 - Esquema do equipamento para a realização da ultrafiltração

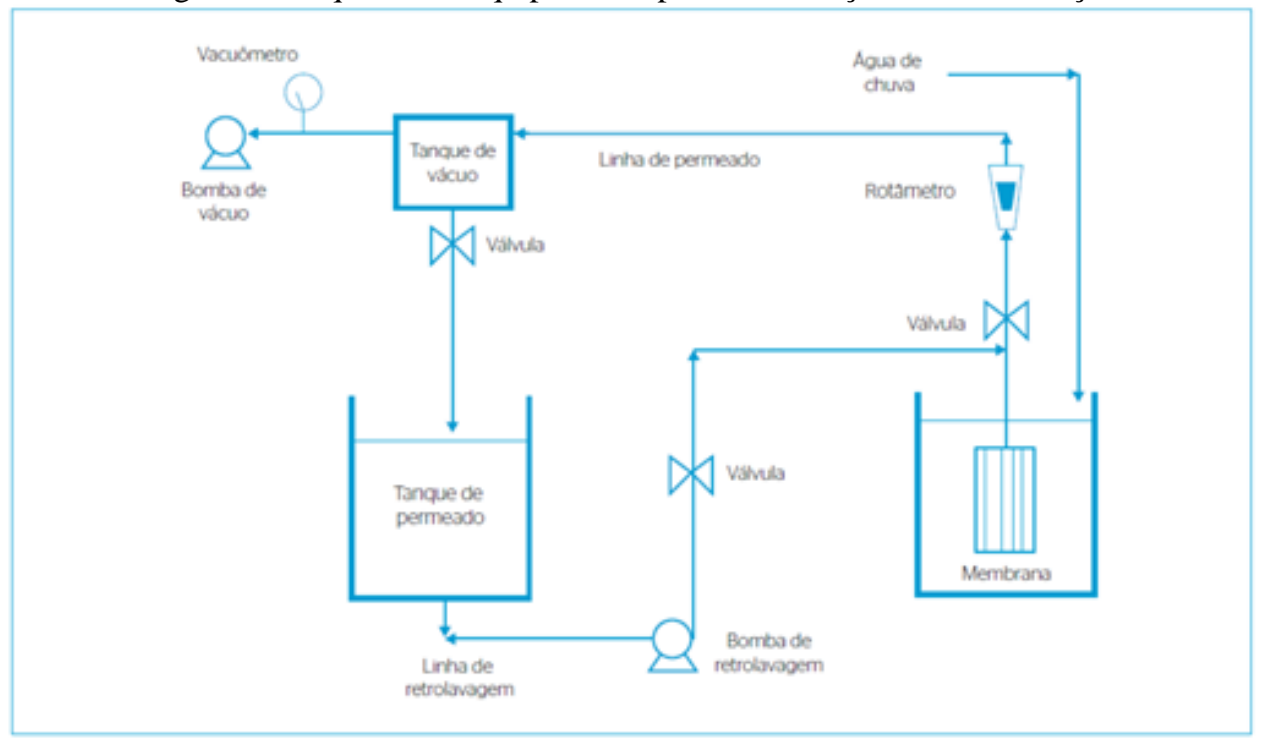

Fonte: MIORANDO, 2017

A água da chuva e do permeado, foram analisadas em diversos parâmetros, para provar a sua potabilidade. Os parâmetros diários foram condutividade, $\mathrm{pH}$ e turbidez, os semanais foram ácidos húmicos, alcalinidade, coliformes totais, dureza, E. coli, fósforo, matéria orgânica, nitrogênio amoniacal, nitrogênio kjeldahl, sólidos suspensos totais, sólidos totais, sulfatos e ainda os mensais, como DBO, nitratos e nitritos.

Foi realizada a UF diária por um período de 3 h, 5 (cinco) dias por semana, desde o mês de fevereiro. No equipamento é possível coletar dados como pressão, volume de permeado coletado e fluxo de filtração, o qual varia durante a filtração dependendo do material suspenso presente.

A cada 90 min, aproximadamente, quando o fluxo reduz, é realizada a retrolavagem com duração de 60 s no equipamento, ativando a bomba de retrolavagem para a limpeza dos poros, sendo realizada a purga desta água. Quando o fluxo reduz e não conseguimos recuperá-lo com a retrolavagem, é realizada a limpeza química da membrana, básica e ácida, respectivamente, com objetivo de recuperar o fluxo limpando os poros.

Após a UF, a água é armazenada em um reservatório interno e são dosados valores entre 0,2 a $2 \mathrm{mg} / \mathrm{L}$ de cloro residual livre, de acordo com a Portaria de Consolidação $\mathrm{n}^{\circ} 5$ de 28 de setembro de 2017.

\section{RESULTADOS}

Os resultados das análises da água da chuva e do permeado sem a adição do cloro estão descrito na Tabela 1. Foi realizada a média dos valores obtidos durante os três meses. 


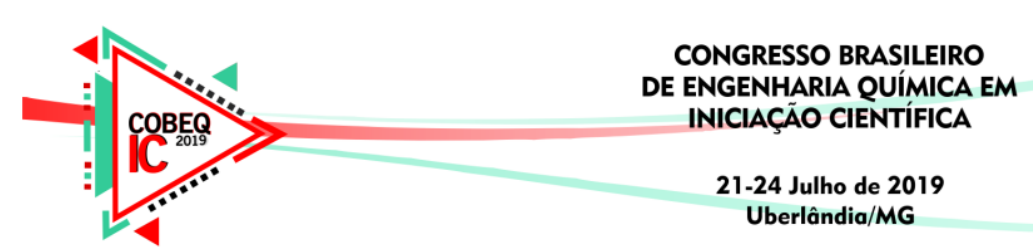

Tabela 1 - Resultados das análises das águas da chuva e do permeado

\begin{tabular}{|c|c|c|c|}
\hline Parâmetro & $\begin{array}{l}\text { Água da } \\
\text { chuva }\end{array}$ & Permeado & $\begin{array}{c}\text { Limites Portaria } \\
n^{\circ} 5 / 2017\end{array}$ \\
\hline Ácidos húmicos (absorbância a 254 nm) & 0,011 & 0,006 & NA \\
\hline Alcalinidade total $\left(\mathrm{mg} \cdot \mathrm{L}^{-1}\right.$ de $\left.\mathrm{CaCO}_{3}\right)$ & 15,5 & 15,5 & NA \\
\hline Coliformes totais (UFC/mL) & $>16$ & $<1,1$ & Aus. em $100 \mathrm{ml}$ \\
\hline Condutividade $\left(\mu \mathrm{S} . \mathrm{cm}^{-1}\right)$ & 36,09 & 35,66 & NA \\
\hline DBO & 10,5 & 5,25 & NA \\
\hline Dureza total $\left(\mathrm{mg} \cdot \mathrm{L}^{-1}\right.$ de $\left.\mathrm{CaCO}_{3}\right)$ & 10,66 & 8 & 500 \\
\hline E. coli $(\mathrm{UFC} / 100 \mathrm{ml})$ & $>16$ & Aus. em $100 \mathrm{ml}$ & Aus. em $100 \mathrm{ml}$ \\
\hline Fósforo (mg.L $\left.\mathrm{L}^{-1}\right)$ & 0,019 & 0,007 & NA \\
\hline Matéria Orgânica (mg.L $\mathrm{L}^{-1}$ de $\mathrm{O}_{2}$ ) & 1,06 & 0,7 & NA \\
\hline Nitrato $\left(\mathrm{mg} . \mathrm{L}^{-1}\right)$ & 0,07 & 0,07 & 10 \\
\hline Nitrito (mg. $\left.\mathrm{L}^{-1}\right)$ & 0,064 & 0,041 & 1 \\
\hline Nitrogênio Amoniacal $\underline{\left(\mathrm{mg} . \mathrm{L}^{-1}\right)}$ & 0,002 & 0,001 & NA \\
\hline Nitrogênio Kjedahl $\underline{\left(\mathrm{mg} . \mathrm{L}^{-1}\right)}$ & 0,042 & 0,042 & NA \\
\hline $\mathrm{pH}$ & 7,4 & 7,35 & 6 a 9 \\
\hline Sólidos suspensos totais $\left(\mathrm{mg} \cdot \mathrm{L}^{-1}\right)$ & 16 & 9 & NA \\
\hline Sólidos totais (mg.L $\left.\mathrm{L}^{-1}\right)$ & 83 & 66 & 1000 \\
\hline Sulfatos $\left(\mathrm{mg} \cdot \mathrm{L}^{-1}\right)$ & 0,05 & 0,05 & 250 \\
\hline Turbidez (NTU) & 0,92 & 0,03 & 2 \\
\hline
\end{tabular}

NA: não aplicável. Aus: Ausência.

Fonte: Autores, 2019

\section{CONCLUSÕES}

A água da chuva que passou pelo processo de UF apresenta qualidade que atende às normativas da Portaria de Consolidação $n^{\circ} 5$ de 28 de setembro de 2017. O processo se demonstra capaz de tornar a água da chuva em água potável, para possível abastecimento. A água da chuva representa uma fonte de fácil captação, sendo que apenas o processo de UF e a adição de cloro é suficiente para torná-la potável, sem necessidade de gastos com perfurações de poços ou com grandes áreas para tratamento físico-químico de águas superficiais. 


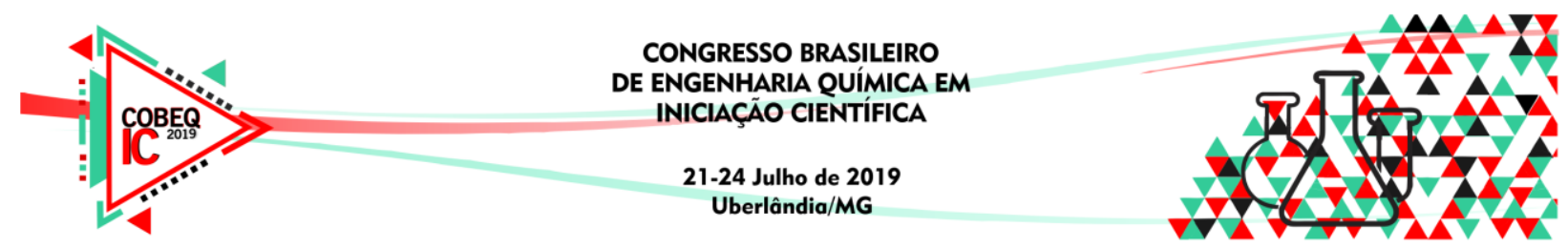

\section{REFERÊNCIAS}

BAÚ, S. R. C. Análise técnica e econômica da ultrafiltração de água da chuva para fins de potabilidade utilizando energia fotovoltaica. Projeto de pesquisa (Pós-graduação em engenharia civil e ambiental), Universidade de Passo Fundo, 2018.

BRASIL. Ministério da Saúde. Portaria de Consolidação no 5 de 28 de setembro de 2017.

MIORANDO, T., BRIÃO, V. B., GIRARDELLI, L., Potabilização de água da chuva por ultrafiltração. Eng. San. Ambient., v. 22, n. 3, p. 481-490, 2017.

OLIVEIRA, T. F. Tratamento de água para abastecimento público por sistema de separação por membrana de ultrafiltração: estudo de caso na ETA Alto da Boa Vista (São Paulo - SP). Dissertação de mestrado (Departamento de Engenharia Hidráulica e Sanitária), Escola Politécnica da Universidade de São Paulo, 2010.

BRIÃO, V. B., TAVARES, C. R. G., Nota Científica: Ultrafiltração de efluente da indústria de laticínios para recuperação de nutrientes: efeito da pressão e da velocidade tangencial. Brazilian Journal of Foof Technology., v. 15, n. 4, p. 352-362, 2012. 